\title{
Progress and Prospects of Long Noncoding RNAs (IncRNAs) in Hepatocellular Carcinoma
}

\author{
Chen Li Jing Chen Kai Zhang Bing Feng Rui Wang Longbang Chen \\ Department of Medical Oncology, Jinling Hospital, School of Medicine, Nanjing University, Nanjing, \\ China
}

\section{Key Words}

Hepatocellular carcinoma $\bullet$ Long noncoding RNA • Diagnosis $・$ Prognosis

\begin{abstract}
Hepatocellular carcinoma (HCC) is one of the most frequently occurring cancers with poor prognosis, and novel diagnostic or prognostic biomarkers and therapeutic targets for HCC are urgently required. With the advance of high-resolution microarrays and massively parallel sequencing technology, IncRNAs are suggested to play critical roles in the tumorigenesis and development of human HCC. To date, dysregulation of many HCC-related IncRNAs such as HULC, HOTAIR, MALAT1, and H19 have been identified. From transcriptional "noise" to indispensable elements, IncRNAs may re-write the central dogma. Also, IncRNAs found in body fluids have demonstrated their utility as fluid-based noninvasive markers for clinical use and as therapeutic targets for HCC. Even though several IncRNAs have been characterized, the underlying mechanisms of their contribution to HCC remain unknown, and many important questions about IncRNAs need resolving. A better understanding of the molecular mechanism in HCC-related IncRNAs will provide a rationale for novel effective IncRNA-based targeted therapies. In this review, we highlight the emerging roles of IncRNAs in HCC, and discuss their potential clinical applications as biomarkers for the diagnosis, prognosis, monitoring and treatment of HCC.

\section{Introduction}

In the last decade, HCC has become one of the most frequently occurring cancers, and is considered to be highly lethal, accounting for approximately one-third of cancer-related

C. Li and J. Chen contributed equally to this work.

Rui Wang

Longbang Chen
Department of Medical Oncology, Jinling Hospital, School of Medicine, Nanjing

University, Nanjing, Jiangsu 210002 (China)

E-Mail wangrui218@163.com and E-Mail chenlongbang@yeah.net 
deaths worldwide $[1,2]$. HBV or HCV infection, alcohol and tobacco use and liver cirrhosis are the major causes of HCC $[2,3]$. Despite advances in the understanding of the molecular mechanisms underlying HCC and improved treatments for HCC, the overall survival time is still limited.

Based on the central dogma, the role of protein-coding genes in the pathogenesis of HCC has been the focal point of research. However, with the advance of technologies such as high-resolution microarray and massively parallel sequencing, non-coding transcripts including small transcripts ( $<200$ nucleotides in length) and long non-coding RNAs ( $>200$ nucleotides in length), which were previously regarded as transcriptional noise or garbage for their lack of coding ability, have been highlighted, and have been characterized and functionally annotated [4-6]. Based on previous experimental studies, it is well accepted that small ncRNAs including miRNAs play vital roles in the regulation of gene expression by transcriptional and post-transcriptional destabilization [7, 8]. More recently, while lncRNAs are among the least well-studied transcripts, functional studies have revealed that lncRNAs transcribed by RNA polymerase II are associated with the carcinogenesis of several cancers including HCC [9]. Recent studies indicated that HCC-related lncRNAs play critical regulatory roles in the development and progression of HCC, while their dysregulation is associated with diverse biological processes including proliferation, differentiation, apoptosis, invasion, and metastasis $[10,11]$ (Table 1 ).

Investigation of HCC-associated lncRNAs and their biological functions are important for understanding the development and progression of HCC, and hence enable the production of more efficient treatments. Here, we briefly outline lncRNAs and highlight the prospects of several major HCC-related lncRNAs.

\section{Characteristics of IncRNAs}

LncRNAs can be classified into five categories based on their location relative to neighboring protein-coding genes: (i) sense, lncRNA overlaps with the sense strand of a protein-coding gene; (ii) antisense, lncRNA overlaps one or more exons of a protein-coding gene on the opposite strand and initiate 3 ' of a protein-coding gene; (iii) bidirectional, the expression of an IncRNA and a protein-coding gene on the opposite strand are initiated $<1,000$ base pairs away in close genomic proximity; (iv) intronic, lncRNA initiated completely within an intron of a protein-coding gene without overlapping exons; (v) intergenic (also termed large intervening non-coding RNAs or lincRNAs), IncRNA located near no other proteincoding loci [12-17] (Fig. 1).

Given that structural studies of IncRNAs are in their infancy, we describe the existing structural data for lncRNAs. Primary, secondary and tertiary structures are the three basic levels of lncRNA structure and sequence composition [17]. Insights into the structural architecture of lncRNAs provide a better understanding of the molecular mechanisms responsible for functional lncRNAs. As the fundamental components of functional lncRNAs for Watson-Crick base pairing and mediation of unpaired regions [18], secondary structures also have duplexes, bulges, hairpins, internal loops and junctions that can provide binding sites for proteins. Moreover, the high-level structure of lncRNAs provides interacting interfaces as well as maintaining lncRNA stability by the triple helix at the 3' lncRNA end, which is used to stabilize poly(A) tail-lacking lncRNAs [19].

\section{Functions and pathways involving IncRNAs targets}

To date, numerous oncogenic genes have been confirmed as targets for HCC-related lncRNAs (Table 1). For example, lncRNAs can suppress cancer cell metastasis by targeting related genes such as HBx, AKT1, GSK3B, Cdc25A, E2F1, hnRNP U, PCAF, GF, PCAF, DMR, ICR, IGF2 and P53 [15, 20-35]. Moreover, affecting apoptosis by DNMT, ABCG2 and TSA also 
Table 1. HCC-related IncRNAs

\begin{tabular}{|c|c|c|c|c|c|}
\hline $\begin{array}{l}\text { Type } \\
\text { lncRNA }\end{array}$ & Name & Expression & $\begin{array}{l}\text { Biological function } \\
\text { in HCC }\end{array}$ & Targeted genes & Reference \\
\hline \multirow[t]{3}{*}{ Sense } & Dreh & Down & $\begin{array}{l}\text { Suppress } \\
\text { metastasis }\end{array}$ & $\mathrm{HBx}$ & [29] \\
\hline & MVIH & UP & $\begin{array}{l}\text { Promote } \\
\text { angiogenesis }\end{array}$ & PGK1 & [57] \\
\hline & RERT & UP & Not clear & EGLN2 & [33] \\
\hline \multirow[t]{3}{*}{ Antisense } & HOTAIR & UP & $\begin{array}{l}\text { Promote } \\
\text { metastasis }\end{array}$ & $\begin{array}{l}\text { HOXD/VEGF /MMP-9 } \\
\mathrm{PRC} 2 / \mathrm{H} 3 \mathrm{~K} 27 / \mathrm{rbm} 38\end{array}$ & {$[53,56]$} \\
\hline & LALR1 & UP & $\begin{array}{l}\text { Promote } \\
\text { proliferation }\end{array}$ & $\operatorname{Axin} 1$ & [48] \\
\hline & PCNA-AS1 & UP & $\begin{array}{l}\text { Promote } \\
\text { proliferation }\end{array}$ & PCNA & [39] \\
\hline \multirow[t]{15}{*}{ Intergenic } & H19 & Down & $\begin{array}{l}\text { Suppress } \\
\text { metastasis }\end{array}$ & $\begin{array}{l}\text { AKT/GSK-3ß/Cdc25A/E2F1 } \\
\text { hnRNP U/PCAF/RNAPol II } \\
\text { IGF/PCAF/DMR/ICR/IGF2 }\end{array}$ & $\begin{array}{l}{[20-24, \quad 26-28,} \\
30-32,34]\end{array}$ \\
\hline & HULC & UP & $\begin{array}{l}\text { Promote } \\
\text { proliferation }\end{array}$ & P18/PRKÁCB /CREB & {$[40,41,44,51]$} \\
\hline & MALAT-1 & UP & $\begin{array}{l}\text { Promote } \\
\text { metastasis }\end{array}$ & $\begin{array}{l}\text { caspase-3/-8/Bax/Bcl-2/ } \\
\text { BclxL }\end{array}$ & {$[52,55]$} \\
\hline & GAS5 & Down & $\begin{array}{l}\text { Suppress } \\
\text { proliferation }\end{array}$ & P53 & [25] \\
\hline & PVT1 & UP & $\begin{array}{l}\text { Promote } \\
\text { proliferation }\end{array}$ & TGF- $\beta 1 /$ NOP2 & [50] \\
\hline & URHC & UP & $\begin{array}{l}\text { Promote } \\
\text { proliferation }\end{array}$ & ZAK & [47] \\
\hline & ROR & UP & $\begin{array}{l}\text { Promote } \\
\text { proliferation }\end{array}$ & TGF $\beta$ & {$[43,49]$} \\
\hline & VLDLR & UP & Suppress apoptosis & ABCG2 & [37] \\
\hline & АТВ & UP & $\begin{array}{l}\text { Promote } \\
\text { metastasis }\end{array}$ & ZEB /IL-11 & [54] \\
\hline & TUC339 & UP & $\begin{array}{l}\text { Promote } \\
\text { proliferation }\end{array}$ & Not clear & [42] \\
\hline & KCNQ1OT1 & UP & Not clear & CDKN1C & [35] \\
\hline & uc002mbe. 2 & Down & Induce apoptosis & TSA & [36] \\
\hline & LALR1 & UP & $\begin{array}{l}\text { Promote } \\
\text { proliferation }\end{array}$ & Axin1/ CTCF/ cyclin D1 & [48] \\
\hline & MEG3 & Down & Induce apoptosis & DNMT & {$[34,38]$} \\
\hline & HEIH & UP & $\begin{array}{l}\text { Promote } \\
\text { proliferation }\end{array}$ & $\mathrm{EZH} 2$ & [45] \\
\hline Intronic & LET & Down & $\begin{array}{l}\text { Suppress } \\
\text { metastasis }\end{array}$ & P53 & [15] \\
\hline Bidirectional & HOTTIP & UP & $\begin{array}{l}\text { Promote } \\
\text { proliferation }\end{array}$ & WDR5/MLL & [46] \\
\hline
\end{tabular}

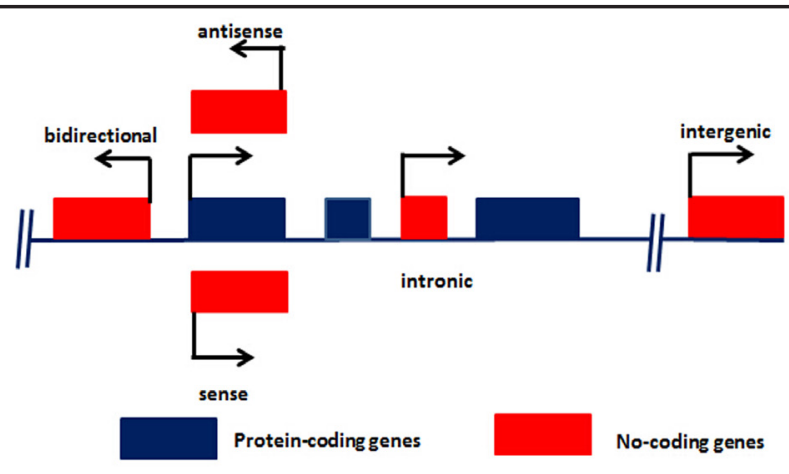

Fig. 1. Overview of five categories of IncRNAs. (a) Sense, lncRNA overlaps with the sense strand of a protein-coding gene; (b) antisense, lncRNA overlap ones or more exons of a protein-coding gene on the opposite strand and is initiated at the 3' end of a protein-coding gene; (c) bidirectional, the expression of an IncRNA and a protein-coding gene on the opposite strand are initiated at $<1,000$ base pairs away in close genomic proximity; (d) Intronic, IncRNA initiated completely within an intron of a protein-coding gene without overlapping exons; (e) Intergenic, IncRNA located near no other protein-coding loci.

contributes to lncRNA-medicated tumor growth [34, 36-38]. Regulation of some growth factor-related genes such as Axin1, PCNA, TGF- $\beta 1$, ZAK, CTCF, cyclin D1, EZH2, WDR5, P18, 


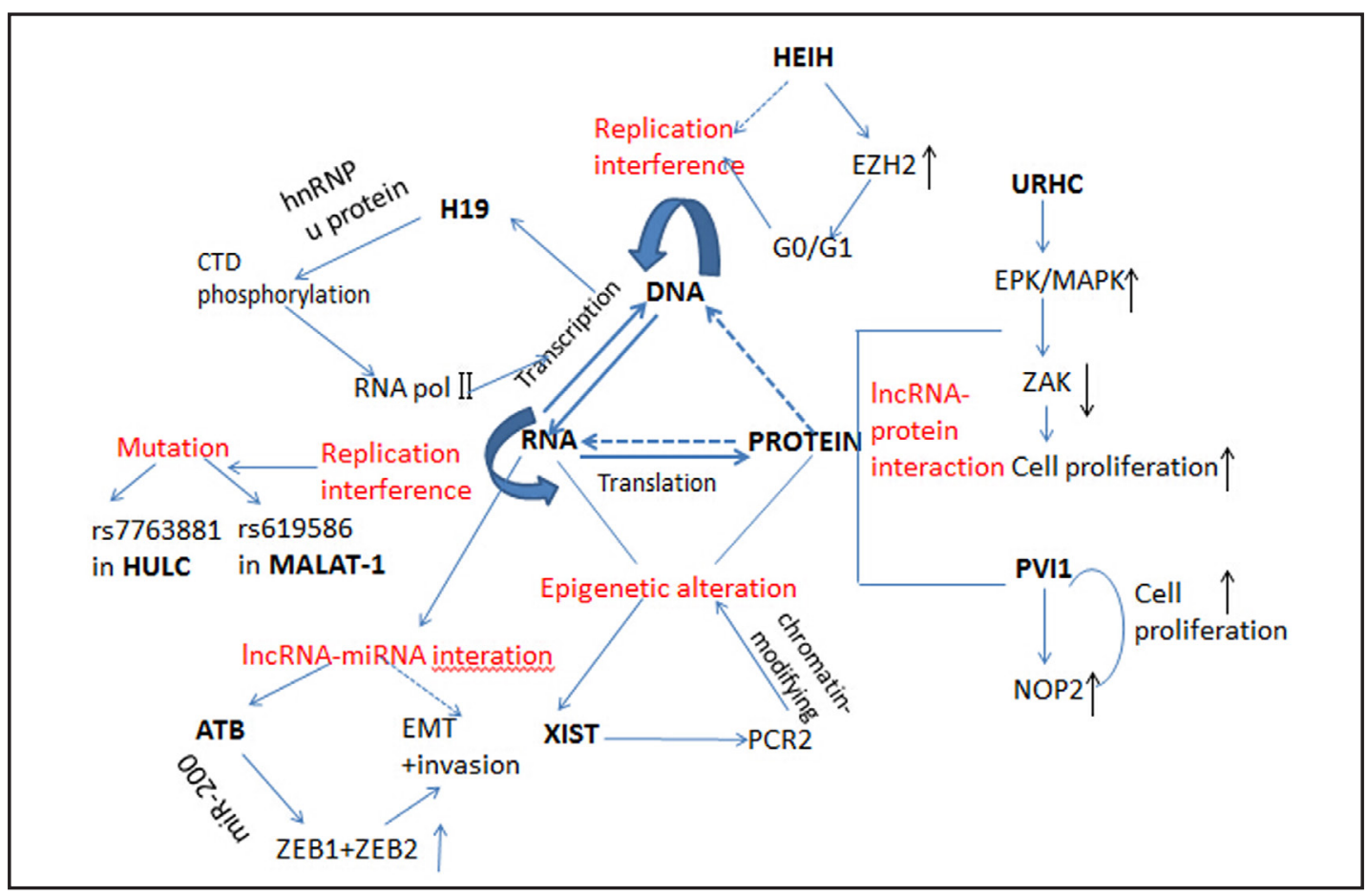

Fig. 2. Paradigms for cellular functions of lncRNAs. LncRNAs can influence almost every cellular behavior of the central-dogma, from transcription to translation by diverse mechanisms including epigenetic alterations, IncRNA-miRNA interactions, protein-lncRNA interactions and genetic variations.

PRKACB, CREB and MLL has been identified in HCC [25, 35, 39-51]. In addition, there is evidence that lncRNAs have important roles in promoting metastasis by targeting factors such as HOXD, VEGF, MMP-9, PRC2, H3K27, RBM38, caspase-3/-8, Bax, Bcl-2, BclxL, ZEB, and IL$11[23,33,52-56]$. Moreover, lncRNA can inhibit angiogenesis by targeting PGK1 [13, 57]. By regulating these related genes, HCC-related lncRNAs exert potent tumor-suppressive effects. However, the number of known target genes is growing quickly, indicating a complicated regulatory network for IncRNAs.

Generally, IncRNAs can influence almost every cellular behavior of the central dogma, from transcription to translation by diverse mechanisms including epigenetic alterations, IncRNA-miRNA/DNA interactions, protein-lncRNA interactions and genetic variations [44, 58-61] (Fig. 2). LncRNA-XIST, which has a well-known essential role in $\mathrm{X}$-chromosome inactivation (XCI), causes stable epigenetic silencing of numerous genes on the $\mathrm{X}$ chromosome during female development by recruiting the crucial chromatinmodifying complex polycomb repressive complex 2 (PRC2) [62]. Another mechanism includes lncRNAs-activated by TGF- $\beta$ (lncRNA-ATB), which upregulates ZEB1 and ZEB2 by competitively binding the miR-200 family to induce the epithelial-mesenchymal transition (EMT) and invasion [54]. In addition, upregulation of LncRNA-HEIH in HCC plays an important role in G0/G1 arrest with cooperation of enhancer of zeste homolog 2 (EZH2), which also requires the repression of the EZH2 target gene [45]. Wang et al. confirmed that the hPVT1-NOP2 cell cycle gene pathway in which plasma-cytoma variant translocation 1 (hPVT1) first upregulates nucleolar protein homolog 2 (NOP2) by enhancing the stability of NOP2 proteins and then the function of hPVT1, which is dependent on the presence of NOP2 proteins and is involved in promoting cell cycling, cell proliferation and carcinogenesis in HCC cells [30]. High expression of upregulated in hepatocellular carcinoma (URHC) can promote cell proliferation and inhibit apoptosis by repressing sterile alpha motif and leucine zipper containing kinase AZK (ZAK) expression through inactivation of the extracellular signalregulated kinase (ERK)/mitogen-activated protein kinases (MAPK) pathway [47]. Similarly, 
by binding to heterogeneous nuclear ribonucleoprotein (hnRNP) U protein, and disrupting the hnRNP U-actin complex, H19 can prevent RNA polymerase II-mediated transcription, which first inhibits the phosphorylation of the RNA Pol II C-terminal domain (CTD) at Ser5 [27]. Surprisingly, the different scale mutations in lncRNAs were also recently revealed to be highly associated with HCC. In a study of 1344 HBV persistent carriers and 1300 HBVpositive HCC patients, Liu et al. found two single nucleotide polymorphisms, rs7763881 in HULC and rs619586 in MALAT1; the data showed that mutations of rs7763881 in HULC were associated with decreased HCC risk, while mutations of rs619586 in MALAT1 were associated with decreased HCC risk with borderline relevance [26].

\section{Dysregulation of several key IncRNAs in HCC}

As a new type of regulator of cellular processes including proliferation, apoptosis, and carcinogenesis, lncRNAs play irreplaceable roles in the progression of HCC. Dysregulation of IncRNAs in HCC marks the spectrum of disease, and has been proposed to be related to hepatocarcinogenesis. Even though the underlying mechanism of HCC-related lncRNAs remains unknown, understanding the differential expression and potential functional roles of lncRNAs in HCC is essential. Accordingly, here we highlight four comparatively known HCC-related lncRNAs: HULC, HOTAIR, MALAT1 and H19.

\section{HULC (highly upregulated in liver cancer)}

Panzitt et al. [40] first reported HULC, which is located on chromosome 6p24.3, as a novel mRNA-like non-coding RNA that is dramatically upregulated in HCC compared with normal liver tissues. In a study by Du et al. [41], the upregulation of HULC medicated by HBx promoted the proliferation of HCC through downregulation of the tumor suppressor gene CDKN2C (p18) at the mRNA and protein level. As a tumor suppressor gene located nearby, CDKN2C was reported to regulate cell cycle and to function within signaling pathways including ATM/ ATR and p53 [41]. Similarly, Wang et al. pointed out that phospho-CREB stimulates HULC expression by interacting with the HULC promoter via a binding site located between -67 and $-53 \mathrm{nt}$, and the upregulated IncRNA-HULC expression acts as an endogenous 'sponge' by interacting with miR-372 [63]. In the cell cycle, inhibition of miR-372 reduced translational repression of the target gene PRKACB, which in turn induced phosphorylation of CREB. The inactive holoenzyme of PKA is composed of two regulatory and two catalytic subunits, which, following splicing of cAMP, joins a dimer of regulatory subunits bound to four cAMP and two free monomeric catalytic subunits [64]. Finally, as the catalytic subunit, PRKACB, through its miR-372 binding site in its 3tsdi, phosphorylates CREB [63]. Based on these results, Wang et al. then speculated that activated CREB protein could recruit histone acetyltransferases including P300 and CBP to the core promoter, which leads to acetylation of the histone tail and open chromatin structure. Ultimately, this kind of mechanism occurring at the proximal promoter provides chromatin accessibility to polymerase II and initiates the transcription of HULC [63]. These findings indicate that the expression of HULC in plasma can be used as a non-invasive promising novel biomarker for the diagnosis and prognosis of HCC.

\section{HOTAIR (HOX transcript antisense RNA)}

HOTAIR is a lincRNA in the HOXC locus located on chromosome 12q13.13, which binds to and targets the PRC2 complex to the HOXD locus and can regulate gene expression by promoting genomic relocalization of PRC2 and H3K27 trimethylation [65, 66]. PRC2 is a histone H3 lysine 27 methylase related to developmental gene silencing and cancer progression [67]. Previous studies on breast cancer metastasis revealed that HOTAIR 
trimethylates H3K27 to repress expression of specific suppressor genes based on PRC2 and polycomb group (PcG) [66]. H3K27 trimethylation can be regulated by the binding of the 5'domain of HOTAIR to PRC2 and the 3'terminus of HOTAIR to the LSD1/CoREST/ REST complex [68]. Notably, HCC patients with high HOTAIR expression had significantly poorer prognoses than those without HOTAIR expression [69]. Inspired by the observation of HOTAIR dysregulation in breast cancer progression, Yang et al. investigated the biology of HOTAIR in HCC progression for the first time and demonstrated that high expression levels of HOTAIR in HCC compared with noncancerous tissues could be used as a candidate biomarker for HCC recurrence and shorter survival [39]. In terms of the specific molecular mechanism of HOTAIR in promoting HCC cell migration and invasion, the finding of Ding et al. suggested that HOTAIR plays a critical role in HCC progression by repressing RNA binding motif protein 38 (RBM38) [70, 71]. This previous study described that RBM38 could be targeted by P53 and induce cell cycle arrest in G1 by stabilizing the CDK inhibitor p21 [72, 73]. Similar to breast cancer, to decrease cell viability and invasion, and increase the sensitivity of cancer cells to doxorubicin and cisplatin, inhibition of HOTAIR by siRNA is potential therapy in a liver cancer cell line.

\section{MALAT1 (metastasis-associated lung adenocarcinoma transcript 1)}

MALAT1, which is expressed in both human and mouse tissues, is also known as nuclear-enriched abundant transcript 2 (NEAT2) and is transcribed from chromosome 11q13. It is upregulated in many solid carcinomas and is associated with cell proliferation and migration through the modulation of caspase-3, caspase-8, Bax, Bcl-2, and Bcl-xL [71]. Tripathi and colleagues demonstrated that MALAT1 localizes to nuclear speckles and interacts with several pre-mRNA splicing factors, acting as a "molecular sponge" and playing a critical role in the balance of the ratios of phosphorylated to dephosphorylated SR proteins [74]. SR proteins are a class of RNA-binding proteins that function in constitutive splicing and alternative splicing (AS), which is a key step in the regulation and diversification of gene function through their sequence-specific recognition of cis-acting exonic splicing enhancers and subsequent recruitment of other splicing factors to facilitate the assembly of the spliceosome [75-77]. At present, it is not clear how MALAT1 alters the ratios of phosphorylated to dephosphorylated SR proteins. A study by Lai et al. [55] was the first to examine the role of IncRNA-MALAT1 in HCC prognosis; following siRNA knockdown of MALAT1, decreased cell proliferation, inhibited migration and invasion as well as multistimuli-induced apoptosis were observed, indicating that silencing MALAT1 activity in HCC might be a vital anticancer therapy. However, MALAT1 regulates endogenous target genes by interacting with a serine/arginine family of nuclear phosphoproteins; as a result, other splicing factors such as C3 and SF2/ASF antigen are influenced and the cellular levels of phosphorylated forms of SR proteins are changed. Then finally, pre-mRNAs such as CTHRC1 and several other motility related genes are modulated by alternative splicing [13].

\section{H19}

As an abundantly rich and conserved transcript, $\mathrm{H} 19$ is a paternally imprinted oncofetal gene and is located at chromosome $11 \mathrm{p} 15.5$, from where it is expressed in embryonic and extra-embryonic cell lineages $[23,28]$. Most reports show that dysregulation of H19 is involved in HCC deterioration. Based on the orthotopic xenograft experiments of Zhang et al. [26], decreased H19 expression in HCC specimens had more regressive and metastatic properties. Moreover, their analysis also indicated that by altering the epigenetic activation of miR-200 with cooperation of the protein complex hnRNP U/PCAF/RNA Pol II, H19 could suppress HCC metastasis and cause EMT. Similarly, based on the conclusion of Jun et al. [78], H19, working together with miR-675, promotes migration and invasion of HCC through the 
AKT/GSK-3 $\beta /$ Cdc25A signaling pathway, providing evidence that this type of lncRNA could be a potent diagnostic biomarker and therapeutic target for HCC.

Even though the functional and regulatory mechanism of HCC-related H19 remains elusive, united epigenetic dysregulation of insulin-like growth factor 2 (IGF2) and H19 is most likely. In most normal adult tissues, only one imprinted gene is expressed; either the paternal allele of IGF2 or the maternal allele of H19 [31]. During HCC, increased expression of IGF2 leads to the expression of $\mathrm{H} 19$ and the loss of adult-type promoter (P1); as a result, the fetal-type promoters (P2-P4) are re-imprinted [23]. Furthermore, multiple systems are involved in transcriptional regulation of the two genes, including an IGF2-H19 endodermal enhancer, a differentially methylated region (DMR) and an imprinted control region (ICR) $[20,30]$. Epigenetic and genetic abnormality at the IGF2 and H19 loci are reported in many studies. Together with these previous studies, Takeda et al. [79] suggested that perturbations of IGF2 and H19 imprinting status occur as tumor-type specific events in the development of HCC [53]. Kim et al. revealed the biallelic expression of H19 and IGF2 in HCC could play a causal role in the epigenetic mechanism, and loss of imprinting (LOI) of IGF2 in HCC was associated with co-expression for H19 and IGF2 [54]. Li et al. reported that HCC-related H19 and IGF2 were regulated in parallel with variable expression levels [55]. Also, Sohda et al. found that the two genes were coordinately overexpressed in 37\% of HCCs, and the almost identical cellular localization and spatiotemporal distribution suggested the presence of a reciprocal relation among the two genes [56]. In conclusion, since the altered transcription of IGF2 and H19 contributes to progression of HCC, the two imprinted genes may potentially be used as monitoring or diagnostic markers for HCC.

\section{LncRNAs as novel biomarkers and therapeutic targets for HCC}

Surgery, chemotherapy and biologics are relatively effective therapies for HCC. However, once it has become metastatic, the majority of HCC remains incurable and has a poor prognosis [80]. Molecular-based tumor predictors are essential for individualized HCC. In the past, cancer-specific miRNAs are widely detectable in the blood, urine, sputum and other biological fluids of patients, thus indicating their suitability as potential biomarkers for diagnosis and prognosis of cancers. Similarly, lncRNAs that are found in body fluids by next generation technologies, including RNA immunoprecipitation, sequencing techniques, microarray, and quantitative real-time PCR, have demonstrated the utility to be used as fluidbased noninvasive markers for clinical use.

For example, further studies indicated that HEIH as an oncogenic IncRNA was significantly associated with the repression of EZH2 and could act as an independent prognostic factor for HCC [81]. A study by Tu et al. proved for the first time that GAS5 (growth arrest-specific transcript 5) expression was decreased in HCC specimens compared with normal matched tissues and could be used as a potential and independent valuable biomarker for predicting the clinical outcome of patients with HCC [25]. Additionally, Takahashi et al. revealed that lincROR was related to the modulation of cellular responses to chemotherapy [63]. Based on this conclusion, molecular-targeted therapy can be used to enhance sensitivity to HCC treatment modalities and improve responses to effective therapeutic agents. As an intercellular signaling mediator and extracellular vesicle-mediated transfer, TUC339 emphasizes the potential for modulating target cell behaviors, which means such an extracellular vesicle lncRNA can be used as a potential marker for HCC [42].

Since lncRNAs can target multiple genes/pathways similarly to miRNAs, re-establishing the expression of a single lncRNA to that of the non-diseased tissue will produce a more pervasive therapeutic effect compared with drugs that obey the one-drug-one-target paradigm [82]. LncRNA replacement therapy will be particularly attractive in the field of oncology, as many lncRNAs exhibit reduced expression in cancer target messenger RNAs of genes that are oncogenic. Further, toxicity may be minimized as lncRNA replacement therapy donates gene products that are already present in the normal tissue. In addition, IncRNAs 
can influence the sensitivity of HCC to chemo- or radiation therapy. Thus, in the future, a better understanding of the molecular mechanism in HCC-related lncRNAs will provide a rationale for novel effective lncRNA-based targeted therapies.

\section{Conclusions and future perspectives}

In recent years, there has been exponential growth in research on the biological functions of lncRNAs in various cancers, including HCC. As one of the most common worldwide diseases, with highly aggressive malignancy and poor prognosis, early diagnosis and discovery of therapeutic targets for HCC is necessary. With application of next generation sequencing and high-resolution of microarray techniques, many studies suggest HCCrelated IncRNAs can influence the initiation, progression and treatment of HCC. LncRNA are defined as transcripts that are longer than 200 nucleotides without obvious protein coding functions, As abovementioned, HCC-related lncRNAs play critical regulatory roles in the progression of HCC while their dysregulation is associated with diverse biological processes [10]. Dysregulation of HULC, HOTAIR, MALAT1, H19 and others has been identified.

Lack of targetable oncogenic driver and the heterogeneous nature of HCC limit the effectiveness of therapies. Molecular-based tumor predictors are essential for individualized HCC. Cancer-specific miRNAs have been widely regarded as potential biomarkers for the diagnosis and prognosis of cancers as they are easily detectable in the blood, urine, sputum and other biological fluids of patients. Similarly, lncRNAs that are found in body fluids have demonstrated the utility to be used as fluid-based non-invasive markers for clinical use. Even though some IncRNAs have been characterized, the underlying mechanism contributing to HCC remains unclear, and it is well accepted that lncRNAs can bring tremendous novel insights into the diagnosis and treatments of HCC. Accordingly, it is foreseeable that formidable efforts will be put in the development of IncRNA-based therapy, but there is a long way to go before they can be used in the prevention and treatment of HCC in the clinic.

In summary, with the rapid developments in genomics, proteomics and bioinformatics, an increasing number of lncRNAs are emerging as novel biomarkers for early diagnosis, better prognostic evaluation and efficient therapeutic targets for HCC in future clinical applications.

\section{Abbreviations}

lncRNAs (long noncoding RNAs); HCC (hepatocellular carcinoma); XCI (X-chromosome inactivation); PRC2 (polycomb repressive complex 2); IncRNA-ATB (lncRNA-activated by TGF- $\beta$ ); EMT (epithelial-mesenchymal transition); EZH2 (enhancer of zeste homolog 2); hPVT1 (plasma-cytoma variant translocation); NOP2 (nucleolar protein homolog 2); URHC (upregulated in hepatocellular carcinoma); ZAK (sterile alpha motif and leucine zipper containing kinase AZK); ERK (extracellular signal-regulated kinase); MAPK (mitogen-activated protein kinases); hnRNP (heterogeneous nuclear ribonucleoprotein); CTD (C-terminal domain); HULC (highly upregulated in liver cancer); HOTAIR (HOX transcript antisense RNA); PcG (polycomb group); MALAT1 (metastasis-associated lung adenocarcinoma transcript 1); NEAT2 (nuclear-enriched abundant transcript 2); IGF2 (insulin-like growth factor 2); DMR (differentially methylated region); ICR (imprinted control region); LOI (loss of imprinting); AFP (elevated alpha-fetoprotein); CEA (carcinoembryonic antigen); GAS5 (growth arrest-specific transcript 5).

\section{Disclosure Statement}

The authors have declared that no competing interest exists. 


\section{Cellular Physiology Cell Physiol Biochem 2015;36:423-434 \begin{tabular}{l|l|l} 
DOI: 10.1159/000430109 & (C) 2015 S. Karger AG, Basel
\end{tabular} www.karger.com/cpb \\ Li et al.: Dysregulation of IncRNAs and HCC Development}

\section{Acknowledgements}

The work was supported by grants from the National Natural Science Foundation of China (No.81172335 and 81472266) and the Excellent Youth Foundation of Jiangsu Province, China (BK20140032). We apologize to all colleagues whose relevant contributions could not be cited due to space limitations.

\section{References}

1 Han LL, Lv Y, Guo H, Ruan ZP, Nan KJ: Implications of biomarkers in human hepatocellular carcinoma pathogenesis and therapy. World J Gastroenterol 2014;20:10249-10261.

2 El-Serag HB, Rudolph KL: Hepatocellular carcinoma: epidemiology and molecular carcinogenesis. Gastroenterology 2007;132:2557-2576.

3 Bertino G, Demma S, Ardiri A, Proiti M, Gruttadauria S, Toro A, Malaguarnera G, Bertino N, Malaguarnera M, Di Carlo I: Hepatocellular carcinoma: novel molecular targets in carcinogenesis for future therapies. Biomed Res Int 2014;2014:203693.

4 Liu H, Song G, Zhou L, Hu X, Liu M, Nie J, Lu S, Wu X, Cao Y, Tao L, Chen L, Qian L: Compared analysis of LncRNA expression profiling in pdk1 gene knockout mice at two time points. Cell Physiol Biochem 2013;32:1497-1508.

5 Wang Y, Gao S, Liu G, Jia R, Fan D, Feng X: Microarray expression profile analysis of long non-coding RNAs in human gastric cardiac adenocarcinoma. Cell Physiol Biochem 2014;33:1225-1238.

6 Kataoka M, Wang DZ: Non-Coding RNAs Including miRNAs and lncRNAs in Cardiovascular Biology and Disease. Cells 2014;3:883-898.

7 Burklew CE, Xie F, Ashlock J, Zhang B: Expression of microRNAs and their targets regulates floral development in tobacco (Nicotiana tabacum). Funct Integr Genomics 2014;14:299-306.

8 Shi X, Wu Y, Ai Z, Liu X, Yang L, Du J, Shao J, Guo Z, Zhang Y: AICAR sustains J1 mouse embryonic stem cell self-renewal and pluripotency by regulating transcription factor and epigenetic modulator expression. Cell Physiol Biochem 2013;32:459-475.

9 Qiu MT, Hu JW, Yin R, Xu L: Long noncoding RNA: an emerging paradigm of cancer research. Tumour Biol 2013;34:613-620.

10 Gutschner T, Diederichs S: The hallmarks of cancer: a long non-coding RNA point of view. RNA Biol 2012;9:703-719.

11 Mercer TR, Dinger ME, Mattick JS: Long non-coding RNAs: insights into functions. Nat Rev Genet 2009;10:155-159.

12 Ponting CP, Oliver PL, Reik W: Evolution and functions of long noncoding RNAs. Cell 2009, 136:629-641.

13 Huang JL, Zheng L, Hu YW, Wang Q: Characteristics of long non-coding RNA and its relation to hepatocellular carcinoma. Carcinogenesis 2014, 35:507-514.

14 Shi X, Sun M, Liu H, Yao Y, Song Y: Long non-coding RNAs: a new frontier in the study of human diseases. Cancer Lett 2013, 339:159-166.

15 He Y, Meng XM, Huang C, Wu BM, Zhang L, Lv XW, Li J: Long noncoding RNAs: Novel insights into hepatocelluar carcinoma. Cancer Lett 2014, 344:20-27.

16 Wang Z, Li X: The role of noncoding RNA in hepatocellular carcinoma. Gland Surg 2013, 2:25-29.

17 Li CH, Chen Y: Targeting long non-coding RNAs in cancers: progress and prospects. Int J Biochem Cell Biol 2013, 45:1895-1910.

18 Wan Y, Kertesz M, Spitale RC, Segal E, Chang HY: Understanding the transcriptome through RNA structure. Nat Rev Genet 2011;12:641-655.

19 Jayaraj GG, Pandey S, Scaria V, Maiti S: Potential G-quadruplexes in the human long non-coding transcriptome. RNA Biol 2012;9:81-86.

20 Wu J, Qin Y, Li B, He WZ, Sun ZL: The aberrant imprinting of insulin-like growth factor II and H19 in human hepatocellular carcinoma. Sichuan Da Xue Xue Bao Yi Xue Ban 2007;38:49-52.

21 Lv J, Yu YQ, Li SQ, Luo L, Wang Q: Aflatoxin B1 promotes cell growth and invasion in hepatocellular carcinoma HepG2 cells through H19 and E2F1. Asian Pac J Cancer Prev 2014;15:2565-2570. 


\section{Cellular Physiology Cell Physiol Biochem 2015;36:423-434 \begin{tabular}{l|l|l}
\hline DOI: 10.1159/000430109 & (C)15 S. Karger AG, Basel
\end{tabular}

22 Kim KS, Lee YI: Biallelic expression of the H19 and IGF2 genes in hepatocellular carcinoma. Cancer Lett 1997;119:143-148.

23 Amit D, Hochberg A: Development of targeted therapy for a broad spectrum of cancers (pancreatic cancer, ovarian cancer, glioblastoma and HCC) mediated by a double promoter plasmid expressing diphtheria toxin under the control of H19 and IGF2-P4 regulatory sequences. Int J Clin Exp Med 2012;5:296-305.

24 Li X, Nong Z, Ekstrom C, Larsson E, Nordlinder H, Hofmann WJ, Trautwein C, Odenthal M, Dienes HP, Ekstrom TJ, Schirmacher P: Disrupted IGF2 promoter control by silencing of promoter P1 in human hepatocellular carcinoma. Cancer Res 1997;57:2048-2054.

25 Tu ZQ, Li RJ, Mei JZ, Li XH: Down-regulation of long non-coding RNA GAS5 is associated with the prognosis of hepatocellular carcinoma. Int J Clin Exp Pathol 2014;7:4303-4309.

26 Zhang L, Yang F, Yuan JH, Yuan SX, Zhou WP, Huo XS, Xu D, Bi HS, Wang F, Sun SH: Epigenetic activation of the MiR-200 family contributes to H19-mediated metastasis suppression in hepatocellular carcinoma. Carcinogenesis 2013;34:577-586.

27 Bi HS, Yang XY, Yuan JH, Yang F, Xu D, Guo YJ, Zhang L, Zhou CC, Wang F, Sun SH: H19 inhibits RNA polymerase II-mediated transcription by disrupting the hnRNP U-actin complex. Biochim Biophys Acta 2013;1830:4899-4906.

28 Keniry A, Oxley D, Monnier P, Kyba M, Dandolo L, Smits G, Reik W: The H19 lincRNA is a developmental reservoir of miR-675 that suppresses growth and Igf1r. Nat Cell Biol 2012;14:659-665.

29 Huang JF, Guo YJ, Zhao CX, Yuan SX, Wang Y, Tang GN, Zhou WP, Sun SH: Hepatitis B virus X protein (HBx)related long noncoding RNA (lncRNA) down-regulated expression by HBx (Dreh) inhibits hepatocellular carcinoma metastasis by targeting the intermediate filament protein vimentin. Hepatology 2013;57:18821892.

30 Wu J, Qin Y, Li B, He WZ, Sun ZL: Hypomethylated and hypermethylated profiles of H19DMR are associated with the aberrant imprinting of IGF2 and H19 in human hepatocellular carcinoma. Genomics 2008;91:443450 .

31 Iizuka N, Oka M, Tamesa T, Hamamoto Y, Yamada-Okabe H: Imbalance in expression levels of insulin-like growth factor 2 and H19 transcripts linked to progression of hepatocellular carcinoma. Anticancer Res 2004;24:4085-4089.

32 Sohda T, Iwata K, Soejima H, Kamimura S, Shijo H, Yun K: In situ detection of insulin-like growth factor II (IGF2) and H19 gene expression in hepatocellular carcinoma. J Hum Genet 1998;43:49-53.

33 Zhu Z, Gao X, He Y, Zhao H, Yu Q, Jiang D, Zhang P, Ma X, Huang H, Dong D, Wan J, Gu Z, Jiang X, Yu L, Gao Y: An insertion/deletion polymorphism within RERT-lncRNA modulates hepatocellular carcinoma risk. Cancer Res 2012;72:6163-6172.

34 Braconi C, Kogure T, Valeri N, Huang N, Nuovo G, Costinean S, Negrini M, Miotto E, Croce CM, Patel T: microRNA-29 can regulate expression of the long non-coding RNA gene MEG3 in hepatocellular cancer. Oncogene 2011;30:4750-4756.

35 Wan J, Huang M, Zhao H, Wang C, Zhao X, Jiang X, Bian S, He Y, Gao Y: A novel tetranucleotide repeat polymorphism within KCNQ10T1 confers risk for hepatocellular carcinoma. DNA Cell Biol 2013;32:628634.

36 Yang H, Zhong Y, Xie H, Lai X, Xu M, Nie Y, Liu S, Wan YJ: Induction of the liver cancer-down-regulated long noncoding RNA uc002mbe.2 mediates trichostatin-induced apoptosis of liver cancer cells. Biochem Pharmacol 2013;85:1761-1769.

37 Takahashi K, Yan IK, Wood J, Haga H, Patel T: Involvement of Extracellular Vesicle Long Noncoding RNA (linc-VLDLR) in Tumor Cell Responses to Chemotherapy. Mol Cancer Res 2014;12:1377-1387.

38 Anwar SL, Krech T, Hasemeier B, Schipper E, Schweitzer N, Vogel A, Kreipe H, Lehmann U: Loss of imprinting and allelic switching at the DLK1-MEG3 locus in human hepatocellular carcinoma. PLoS One 2012;7:e49462.

39 Yuan SX, Tao QF, Wang J, Yang F, Liu L, Wang LL, Zhang J, Yang Y, Liu H, Wang F, Sun SH, Zhou WP: Antisense long non-coding RNA PCNA-AS1 promotes tumor growth by regulating proliferating cell nuclear antigen in hepatocellular carcinoma. Cancer Lett 2014;349:87-94.

40 Panzitt K, Tschernatsch MM, Guelly C, Moustafa T, Stradner M, Strohmaier HM, Buck CR, Denk H, Schroeder R, Trauner M, Zatloukal K: Characterization of HULC, a novel gene with striking up-regulation in hepatocellular carcinoma, as noncoding RNA. Gastroenterology 2007;132:330-342. 
41 Du Y, Kong G, You X, Zhang S, Zhang T, Gao Y, Ye L, Zhang X: Elevation of highly up-regulated in liver cancer (HULC) by hepatitis B virus X protein promotes hepatoma cell proliferation via down-regulating p18. J Biol Chem 2012;287:26302-26311.

42 Kogure T, Yan IK, Lin WL, Patel T: Extracellular Vesicle-Mediated Transfer of a Novel Long Noncoding RNA TUC339: A Mechanism of Intercellular Signaling in Human Hepatocellular Cancer. Genes Cancer 2013;4:261-272.

43 Takahashi K, Yan IK, Kogure T, Haga H, Patel T: Extracellular vesicle-mediated transfer of long non-coding RNA ROR modulates chemosensitivity in human hepatocellular cancer. FEBS Open Bio 2014;4:458-467.

44 Liu Y, Pan S, Liu L, Zhai X, Liu J, Wen J, Zhang Y, Chen J, Shen H, Hu Z: A genetic variant in long non-coding RNA HULC contributes to risk of HBV-related hepatocellular carcinoma in a Chinese population. PLoS One 2012; 7:e35145.

45 Yang F, Zhang L, Huo XS, Yuan JH, Xu D, Yuan SX, Zhu N, Zhou WP, Yang GS, Wang YZ, Shang JL, Gao CF, Zhang FR, Wang F, Sun SH: Long noncoding RNA high expression in hepatocellular carcinoma facilitates tumor growth through enhancer of zeste homolog 2 in humans. Hepatology 2011;54:1679-1689.

46 Quagliata L, Matter MS, Piscuoglio S, Arabi L, Ruiz C, Procino A, Kovac M, Moretti F, Makowska Z, Boldanova T, Andersen JB, Hammerle M, Tornillo L, Heim MH, Diederichs S, Cillo C, Terracciano LM: Long noncoding RNA HOTTIP/HOXA13 expression is associated with disease progression and predicts outcome in hepatocellular carcinoma patients. Hepatology 2014;59:911-923.

47 Xu WH, Zhang JB, Dang Z, Li X, Zhou T, Liu J, Wang DS, Song WJ, Dou KF: Long non-coding RNA URHC regulates cell proliferation and apoptosis via ZAK through the ERK/MAPK signaling pathway in hepatocellular carcinoma. Int J Biol Sci 2014;10:664-676.

48 Xu D, Yang F, Yuan JH, Zhang L, Bi HS, Zhou CC, Liu F, Wang F, Sun SH: Long noncoding RNAs associated with liver regeneration 1 accelerates hepatocyte proliferation during liver regeneration by activating Wnt/ beta-catenin signaling. Hepatology 2013;58:739-751.

49 Takahashi K, Yan IK, Haga H, Patel T: Modulation of hypoxia-signaling pathways by extracellular linc-RoR. J Cell Sci 2014;127:1585-1594.

50 Wang F, Yuan JH, Wang SB, Yang F, Yuan SX, Ye C, Yang N, Zhou WP, Li WL, Li W, Sun SH: Oncofetal long noncoding RNA PVT1 promotes proliferation and stem cell-like property of hepatocellular carcinoma cells by stabilizing NOP2. Hepatology 2014;60:1278-1290.

51 Xie H, Ma H, Zhou D: Plasma HULC as a promising novel biomarker for the detection of hepatocellular carcinoma. Biomed Res Int 2013;2013:136106.

52 Guo F, Li Y, Liu Y, Wang J, Li Y, Li G: Inhibition of metastasis-associated lung adenocarcinoma transcript 1 in CaSki human cervical cancer cells suppresses cell proliferation and invasion. Acta Biochim Biophys Sin (Shanghai) 2010;42:224-229.

53 Geng YJ, Xie SL, Li Q, Ma J, Wang GY: Large intervening non-coding RNA HOTAIR is associated with hepatocellular carcinoma progression. J Int Med Res 2011;39:2119-2128.

54 Yuan JH, Yang F, Wang F, Ma JZ, Guo YJ, Tao QF, Liu F, Pan W, Wang TT, Zhou CC, Wang SB, Wang YZ, Yang Y, Yang N, Zhou WP, Yang GS, Sun SH: A long noncoding RNA activated by TGF-beta promotes the invasionmetastasis cascade in hepatocellular carcinoma. Cancer Cell 2014;25:666-681.

55 Lai MC, Yang Z, Zhou L, Zhu QQ Xie HY, Zhang F, Wu LM, Chen LM, Zheng SS: Long non-coding RNA MALAT-1 overexpression predicts tumor recurrence of hepatocellular carcinoma after liver transplantation. Med Oncol 2012;29:1810-1816.

56 Yang Z, Zhou L, Wu LM, Lai MC, Xie HY, Zhang F, Zheng SS: Overexpression of long non-coding RNA HOTAIR predicts tumor recurrence in hepatocellular carcinoma patients following liver transplantation. Ann Surg Oncol 2011;18:1243-1250.

57 Yuan SX, Yang F, Yang Y, Tao QF, Zhang J, Huang G, Wang RY, Yang S, Huo XS, Zhang L, Wang F, Sun SH, Zhou WP: Long noncoding RNA associated with microvascular invasion in hepatocellular carcinoma promotes angiogenesis and serves as a predictor for hepatocellular carcinoma patients' poor recurrence-free survival after hepatectomy. Hepatology 2012;56:2231-2241.

58 Zhu J, Liu S, Ye F, Shen Y, Tie Y, Zhu J, Jin Y, Zheng X, Wu Y, Fu H: The long noncoding RNA expression profile of hepatocellular carcinoma identified by microarray analysis. PLoS One 2014;9:e101707.

59 Mohamadkhani A: Long Noncoding RNAs in Interaction With RNA Binding Proteins in Hepatocellular Carcinoma. Hepat Mon 2014;14:e18794. 


\section{Cellular Physiology Cell Physiol Biochem 2015;36:423-434

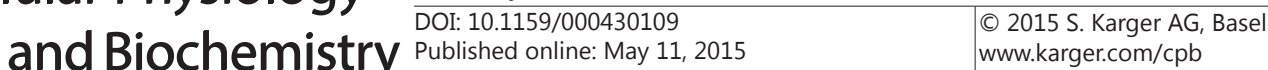 \\ Li et al.: Dysregulation of IncRNAs and HCC Development}

60 Pogribny IP, Rusyn I: Role of epigenetic aberrations in the development and progression of human hepatocellular carcinoma. Cancer Lett 2014;342:223-230.

61 Jalali S, Bhartiya D, Lalwani MK, Sivasubbu S, Scaria V: Systematic transcriptome wide analysis of lncRNAmiRNA interactions. PLoS One 2013;8:e53823.

62 Engreitz JM, Pandya-Jones A, McDonel P, Shishkin A, Sirokman K, Surka C, Kadri S, Xing J, Goren A, Lander ES, Plath K, Guttman M: The Xist lncRNA exploits three-dimensional genome architecture to spread across the X chromosome. Science 2013;341:1237973.

63 Wang J, Liu X, Wu H, Ni P, Gu Z, Qiao Y, Chen N, Sun F, Fan Q: CREB up-regulates long non-coding RNA, HULC expression through interaction with microRNA-372 in liver cancer. Nucleic Acids Res 2010;38:5366-5383.

64 Delghandi MP, Johannessen M, Moens U: The cAMP signalling pathway activates CREB through PKA, p38 and MSK1 in NIH 3T3 cells. Cell Signal 2005;17:1343-1351.

65 Gupta RA, Shah N, Wang KC, Kim J, Horlings HM, Wong DJ, Tsai MC, Hung T, Argani P, Rinn JL, Wang Y, Brzoska P, Kong B, Li R, West RB, van de Vijver MJ, Sukumar S, Chang HY: Long non-coding RNA HOTAIR reprograms chromatin state to promote cancer metastasis. Nature 2010;464:1071-1076.

66 Rinn JL, Kertesz M, Wang JK, Squazzo SL, Xu X, Brugmann SA, Goodnough LH, Helms JA, Farnham PJ, Segal E, Chang HY: Functional demarcation of active and silent chromatin domains in human HOX loci by noncoding RNAs. Cell 2007;129:1311-1323.

67 Ezponda T, Licht JD: Molecular pathways: deregulation of histone h3 lysine 27 methylation in cancerdifferent paths, same destination. Clin Cancer Res 2014;20:5001-5008.

68 Tsai MC, Manor O, Wan Y, Mosammaparast N, Wang JK, Lan F, Shi Y, Segal E, Chang HY: Long noncoding RNA as modular scaffold of histone modification complexes. Science 2010;329:689-693.

69 Ishibashi M, Kogo R, Shibata K, Sawada G, Takahashi Y, Kurashige J, Akiyoshi S, Sasaki S, Iwaya T, Sudo T, Sugimachi K, Mimori K, Wakabayashi G, Mori M: Clinical significance of the expression of long non-coding RNA HOTAIR in primary hepatocellular carcinoma. Oncol Rep 2013;29:946-950.

70 Yu FJ, Zheng JJ, Dong PH, Fan XM: Long non-coding RNAs and hepatocellular carcinoma. Mol Clin Oncol 2015;3:13-17.

71 Lin R, Maeda S, Liu C, Karin M, Edgington TS: A large noncoding RNA is a marker for murine hepatocellular carcinomas and a spectrum of human carcinomas. Oncogene 2007;26:851-858.

72 Guo F, Li Y, Liu Y, Wang J, Li G: Inhibition of metastasis-associated lung adenocarcinoma transcript 1 in CaSki human cervical cancer cells suppresses cell proliferation and invasion. Acta Biochim Biophys Sin (Shanghai) 2010;42:224-229.

73 Shu L, Yan W, Chen X: RNPC1, an RNA-binding protein and a target of the p53 family, is required for maintaining the stability of the basal and stress-induced p21 transcript. Genes Dev 2006;20:2961-2972.

74 Tripathi V, Ellis JD, Shen Z, Song DY, Pan Q, Watt AT, Freier SM, Bennett CF, Sharma A, Bubulya PA, Blencowe BJ, Prasanth SG, Prasanth KV: The nuclear-retained noncoding RNA MALAT1 regulates alternative splicing by modulating SR splicing factor phosphorylation. Mol Cell 2010;39:925-938.

75 Lin S, Fu XD: SR proteins and related factors in alternative splicing. Adv Exp Med Biol 2007;623:107-122.

76 Long JC, Caceres JF: The SR protein family of splicing factors: master regulators of gene expression. Biochem J 2009;417:15-27.

77 Hallegger M, Llorian M, Smith CW: Alternative splicing: global insights. FEBS J 2010;277:856-866.

78 Lv J, Ma L, Chen XL, Huang XH, Wang Q: Downregulation of LncRNAH19 and MiR-675 promotes migration and invasion of human hepatocellular carcinoma cells through AKT/GSK-3beta/Cdc25A signaling pathway. J Huazhong Univ Sci Technolog Med Sci 2014;34:363-369.

79 Takeda S, Kondo M, Kumada T, Koshikawa T, Ueda R, Nishio M, Osada H, Suzuki H, Nagatake M, Washimi 0 , Takagi K, Takahashi T, Nakao A: Allelic-expression imbalance of the insulin-like growth factor 2 gene in hepatocellular carcinoma and underlying disease. Oncogene 1996;12:1589-1592.

80 Blum HE: Hepatocellular carcinoma: therapy and prevention. World J Gastroenterol 2005;11:7391-7400.

81 Gao SB, Xu B, Ding LH, Zheng QL, Zhang L, Zheng QF, Li SH, Feng ZJ, Wei J, Yin ZY, Hua X, Jin GH: The functional and mechanistic relatedness of EZH2 and menin in hepatocellular carcinoma. J Hepatol 2014;61:832-839.

82 Henry JC, Azevedo-Pouly AC, Schmittgen TD: MicroRNA replacement therapy for cancer. Pharm Res 2011;28:3030-3042. 